\title{
Sazonalidade do teor de proteína e outros componentes do leite e sua relação com programa de pagamento por qualidade
}

\author{
[Seasonability of protein and others milk components related with quality payment program] \\ L.C. Roma Júnior ${ }^{1}$, J.F.G. Montoya ${ }^{2}$, T.T. Martins ${ }^{2}$, L.D. Cassoli ${ }^{2}$, P.F. Machado ${ }^{2}$ \\ ${ }^{1}$ Agência Paulista de Tecnologia dos Agronegócios - PRDTA Centro Leste \\ Av. Bandeirantes, 2419 \\ 14030-670 - Ribeirão Preto, SP \\ ${ }^{2}$ Departamento de Zootecnia - ESALQ/USP - Piracicaba, SP
}

\begin{abstract}
RESUMO
Avaliou-se o efeito da variação da qualidade do leite mediante acompanhamento de amostras provenientes de tanques refrigeradores. As 2.970 amostras foram obtidas de outubro/2005 a setembro/2006. Foram realizadas análises de composição, contagem de células somáticas (CCS) e contagem bacteriana total. As condições climáticas foram avaliadas pela temperatura e umidade do ar coletadas em estações meteorológicas distribuídas em todo o estado de São Paulo. No outono, ocorreram os maiores valores para gordura e proteína do leite, 3,65 e 3,21\%, respectivamente. Para contagem de células somáticas, foi observado aumento no verão e contagem bacteriana na época da primavera. Foi identificada a influência da época do ano sobre o preço do leite pago dentro de um programa, com valor de bonificação máxima de 7,9\% para o outono. Um dos mais importantes itens relacionados com a penalização foi a CCS, a qual pode interferir na qualidade dos produtos finais por meio de alteração da proporção de caseína/proteínas do soro. O efeito da CCS e o da época do ano devem ser considerados na formulação das tabelas de programas de pagamento.
\end{abstract}

Palavras-chave: produtor de leite, efeitos climáticos, preço do leite

\begin{abstract}
This study evaluated the variation of quality of bulk tank milk using 2,970 samples, collected from October 2005 to September 2006. Milk composition analyses, somatic cell count (SCC), and total bacterial count were performed. Climate conditions were evaluated by temperature and relative air humidity collected at meteorological stations throughout São Paulo state. Autumn season was related to the highest values for protein and fat, 3.65 and $3.21 \%$, respectively. For somatic cell count, it was observed an increase in the count in the summer and for bacterial count in the spring. The influence of season on milk price was observed for dairy producers in a program, with maximum bonus of $7.9 \%$ in the autumn. One of the most important parameters related to penalty for lower quality of milk was SCC, since it can affect the quality of some dairies by the alteration of casein/whey protein proportion. Therefore, the effects of SCC and season should be considered into the process of formulation of tables for milk payment program.
\end{abstract}

Keywords: dairy industry, climatic effects, milk price

\section{INTRODUÇÃO}

Ao se referir à qualidade do leite, deve-se ater principalmente à qualidade da matéria-prima,

Recebido em 12 de janeiro de 2009

Aceito em 23 de novembro de 2009

E-mail: 1croma@apta.sp.gov.br

Projeto financiado pela FAPESP, processo 05/51369-8 que é ponto de extrema importância no processo de inserção do Brasil no mercado mundial de lácteos. Essa questão envolve mudança radical nas normas de recepção do leite (contagem bacteriana, crioscopia, acidez, células somáticas 
etc.) e introdução de normas de origem (refrigeração na propriedade, coleta a granel e ordenha mecânica), conforme preconizado no Programa de Melhoria da Qualidade do Leite (Alvim e Martins, 2005).

O termo qualidade do leite é muito utilizado devido à importância e ao foco dado à valorização dos componentes do leite na formulação do preço do produto pago ao produtor, especialmente para empresas que pretendem ampliar a participação no mercado de leite fluido e internacional (Álvares, 2005). A determinação de um leite com qualidade pode ser definida em termos de sua integridade, ou seja, livre da adição de substâncias e/ou remoção de componentes; de sua composição química e características físicas; e de sua deterioração microbiológica e presença de patógenos (Dürr, 2004). Monardes (1998) ainda destaca que a qualidade do leite também está relacionada a características organolépticas (odor, sabor, aspecto)

Existem iniciativas governamentais que visam padronizar e melhorar a qualidade do leite, como a implantação de normas nacionais de padrões de qualidade do leite, determinadas pelo Programa Nacional de Melhoria da Qualidade do Leite, do Ministério da Agricultura, Pecuária e Abastecimento (Ribeiro et al., 2000), as quais compõem a Instrução Normativa 51 já em vigor (Instrução..., 2002)

As indústrias de grande porte, no início da década de 90, passaram a estabelecer novos requisitos para o recebimento do leite, vinculando a remuneração ao produtor justamente com a qualidade da matéria-prima, com intuito de instituir de forma progressiva o pagamento diferenciado do produto de acordo com sua qualidade (Fonseca et al., 2006).

Juntamente à iniciativa do governo por meio do Programa Nacional de Melhoria da Qualidade do Leite, algumas indústrias iniciaram a implantação de programas de pagamento por qualidade, como instrumento para incentivar o produtor a buscar pela melhoria de seu produto e, indiretamente, para obter melhor rendimento industrial. Além do pagamento de bonificação pelo leite de alta qualidade, podem ser utilizadas penalizações para o leite de baixa qualidade (Álvares, 2005). Esses programas têm sido ferramentas poderosas para motivar os produtores a melhorar a qualidade do leite cru. Em geral, os incentivos por qualidade variam entre as indústrias ou cooperativas, mas a contagem de células somáticas, a contagem total de bactérias, a ausência de resíduos de antibióticos e outros inibidores são os principais quesitos contemplados para aferir a qualidade do leite (Bandeira, 2004)

Diante do exposto, o objetivo do presente estudo foi avaliar o efeito da sazonalidade dos componentes do leite que fazem parte da classificação utilizada por programas de pagamento por qualidade do leite produzido e, assim, o efeito sobre o preço do leite pago ao produtor.

\section{MATERIAL E MÉTODOS}

Durante 12 meses, de outubro de 2005 a setembro de 2006, foram avaliadas 2.970 amostras de leite $(100 \mathrm{~mL})$ de tanques de expansão, divididas em dois frascos de $50 \mathrm{~mL}$ cada (dois tipos de conservantes) e recebidas refrigeradas $\left(4^{\circ} \mathrm{C}\right)$ pelo laboratório Clínica do Leite da ESALQ/USP, em Piracicaba, SP. A condução do experimento foi realizada com propriedades distribuídas nos estados de Minas Gerais, Rio de Janeiro e São Paulo. As amostras foram coletadas por técnicos do laticínio participante do projeto, os quais receberam treinamento para o correto procedimento de coleta.

Mensalmente, para uma das duas amostras de leite $(50 \mathrm{~mL})$ de cada propriedade, foram realizadas as seguintes análises: composição (gordura, proteína, lactose e extrato seco desengordurado), $\mathrm{pH}$, acidez titulável $\mathrm{e}$ resistência à prova do álcool, sendo que estas amostras, conservadas com Bronopol $\AA$, foram enviadas pelo laticínio. Em experimento anterior, realizado com amostras preservadas com este conservante, não foi observada nenhuma influência deste sobre as análises físico-químicas (Zago et al., 2005). A segunda amostra (50mL), destinada somente à contagem bacteriana total (CBT), foi preservada com o conservante de ação bacteriostático Azidiol (Barcina et al., 1987). Durante todo o processo de logística, as amostras permaneceram sob refrigeração a $4^{\circ} \mathrm{C}$, desde $\mathrm{o}$ momento da coleta até a realização das análises. 
As análises de composição do leite (proteína, gordura, lactose, extrato seco desengordurado) foram realizadas eletronicamente por absorção infravermelha no equipamento Bentley 2000. A contagem de células somáticas (CCS) foi realizada por meio de contagem eletrônica por citometria fluxométrica, utilizando-se o equipamento Bentley Somacount $300^{1}$. A CBT foi analisada por meio da metodologia de citometria de fluxo, utilizando-se o equipamento IBC Bactocount ${ }^{1}$. Para garantir confiabilidade dos registros, foram excluídos valores nulos para contagem bacteriana e contagem de células somáticas, bem como valores de gordura abaixo de $2 \%$ e acima de $5 \%$.

Para avaliação das condições climáticas, foram obtidos dados de temperatura ambiente, umidade relativa, pluviosidade, radiação solar de estações meteorológicas participantes do Centro Integrado de Informações Agrometeorológicas (CIIAGRO) do Instituto Agronômico de Campinas (IAC)/Secretaria de Agricultura e Abastecimento do Estado de São Paulo, além da Estação Meteorológica do Departamento de Ciências Exatas, localizada na Escola Superior de Agricultura "Luiz de Queiroz", Piracicaba, SP.
Para cálculo do índice de conforto térmico e demonstração do efeito da variação climática sobre a qualidade do leite, foi calculado o índice de temperatura e umidade (ITU) proposto por Kelly e Bond (1971). Os valores são calculados a partir da temperatura ambiente e da umidade relativa do ar, conforme a fórmula: $\mathrm{ITU}=\mathrm{T}-$ 0,55 (1- UR)(T-58), em que: $\mathrm{T}=$ temperatura ambiente $\left({ }^{\circ} \mathrm{F}\right)$ e $\mathrm{UR}=$ umidade relativa do ar expressa como um valor decimal.

Para a completa avaliação do efeito da época sobre o pagamento por qualidade, foi realizado um levantamento do preço médio do leite pago aos produtores do Estado de São Paulo, durante o ano de 2005/2006, junto ao Centro de Estudos Avançados em Economia Aplicada (CEPEA), do Departamento de Economia, Administração e Sociologia da ESALQ.

Em relação ao programa de pagamento por qualidade do leite, foi utilizado um exemplo de bonificação/penalização citado por Bandeira (2004), apresentado na Tab. 1.

Tabela 1. Tabelas de valores de bonificação/penalização em função dos parâmetros de qualidade do leite, como gordura, proteína, contagem de células somáticas e contagem bacteriana total

\begin{tabular}{ll}
\hline Gordura $(\%)$ & \\
\hline Maior que 3,40 & Bônus de $6 \%$ para cada ponto percentual \\
Entre $3,30-3,40$ & Sem bônus e sem desconto \\
Menor que 3,30 & Desconto de $6 \%$ para cada ponto percentual \\
\hline Proteína $(\%)$ & Bônus de $6 \%$ para cada ponto percentual \\
\hline Maior que 3,05 & Sem bônus e sem desconto \\
Entre $3,00-3,05$ & Desconto de $6 \%$ para cada ponto percentual \\
Menor que 3,00 & Bônus total de $7 \%$ \\
\hline Contagem de células somáticas (1000 céls $/ \mathrm{mL})$ \\
\hline Limite de bônus $<150$ & Bônus de $1 \%$ para cada redução de 50 céls $/ \mathrm{mL}$ \\
Menor que 450 & Sem bônus e sem desconto \\
Entre $450-500$ & Desconto de $1 \%$ para cada aumento de 50 céls $/ \mathrm{mL}$ \\
Maior que 500 & Desconto total de $7 \%$ \\
Limite de desconto $>750$ & \\
\hline Contagem bacteriana total $(1000 \mathrm{UFC} / \mathrm{mL})$ & \\
\hline Limite de bônus $<25$ & Bônus total de $4 \%$ \\
Menor que 100 & Bônus de $1 \%$ para cada redução de $25 \mathrm{UFC} / \mathrm{mL}$ \\
Entre $100-125$ & Sem bônus e sem desconto \\
Maior que 125 & Desconto de $1 \%$ para cada aumento de $25 \mathrm{UFC} / \mathrm{mL}$ \\
Limite de desconto $>200$ & Desconto total de $5 \%$ \\
\hline Fon
\end{tabular}

Fonte: Bandeira, 2004.

${ }^{1}$ Bentley Instruments Incorporated - Chaska, EUA. 
O delineamento experimental adotado foi $\mathrm{o}$ completamente ao acaso, considerando como fator os meses do ano, e também em análise posterior, o efeito da época do ano. Como as coletas eram realizadas apenas no começo do mês, foram consideradas as estações do ano: primavera (outubro a dezembro), verão (janeiro a março), outono (abril a junho) e inverno (julho a setembro). Os dados foram submetidos à análise de variância, utilizando-se o procedimento GLM, por meio do pacote estatístico SAS/2006, e ao teste Tukey para comparação de médias, com nível de significância para rejeição da hipótese de nulidade de $5 \%$.

\section{RESULTADOS E DISCUSSÃO}

Na Tab. 2 são apresentados os valores médios mensais para cada componente estudado. Para todos os componentes avaliados, foram observadas variações significativas ao longo do ano. Observou-se diferença entre os meses, contudo não foi possível definir o mês com maior ou menor teor (gordura e proteína), ou mesmo para contagem de células somáticas e contagem bacteriana. $\mathrm{O}$ fato de ter sido encontrada diferença dos valores dos componentes para os meses indica existir efeito de mês do ano sobre o pagamento por qualidade. Com exceção do mês de janeiro, ocorreu diminuição nos teores de gordura e proteína nos meses de julho a outubro, com os menores valores nos meses de setembro e outubro. Head (1989) observou variação semelhante nos componentes do leite em função do efeito da época do ano, principalmente para a época de verão. No presente estudo, esse efeito não foi encontrado somente no período de verão (dezembro a março), mas, também, desde o inicio da primavera (setembro).

Tabela 2. Valores mensais médios de gordura, proteína, contagem de células somáticas e contagem bacteriana total de amostras de leite

\begin{tabular}{lcccc}
\hline \multicolumn{1}{c}{ Mês } & $\begin{array}{c}\text { Gordura } \\
(\%)\end{array}$ & $\begin{array}{c}\text { Proteína } \\
(\%)\end{array}$ & $\begin{array}{c}\text { CCS } \\
(1000 \mathrm{cé} / \mathrm{s} / \mathrm{mL})\end{array}$ & $\begin{array}{c}\text { CBT } \\
(1000 \mathrm{U} C / \mathrm{mL})\end{array}$ \\
\hline Out/05 & $3,41 \mathrm{fg}$ & $3,07 \mathrm{~d}$ & $396 \mathrm{~g}$ & 181 \\
Nov/05 & $3,54 \mathrm{~cd}$ & $3,17 \mathrm{~b}$ & $447 \mathrm{fg}$ & $181 \mathrm{~b}$ \\
Dez/05 & $3,49 \mathrm{de}$ & $3,17 \mathrm{~b}$ & $625 \mathrm{abc}$ & 331 \\
Jan/06 & $3,35 \mathrm{~g}$ & $3,07 \mathrm{~d}$ & $701 \mathrm{a}$ & $77 \mathrm{~d}$ \\
Fev/06 & $3,45 \mathrm{ef}$ & $3,18 \mathrm{~b}$ & $655 \mathrm{ab}$ & $111 \mathrm{c}$ \\
Mar/06 & $3,61 \mathrm{~b}$ & $3,28 \mathrm{a}$ & $574 \mathrm{bcde}$ & $76 \mathrm{~d}$ \\
Abr/06 & $3,68 \mathrm{a}$ & $3,27 \mathrm{a}$ & $504 \mathrm{def}$ & $63 \mathrm{def}$ \\
Mai/06 & $3,69 \mathrm{a}$ & $3,19 \mathrm{~b}$ & $559 \mathrm{cde}$ & $47 \mathrm{f}$ \\
Jun/06 & $3,58 \mathrm{bc}$ & $3,16 \mathrm{~b}$ & $576 \mathrm{bcd}$ & $61 \mathrm{def}$ \\
Jul/06 & $3,51 \mathrm{cde}$ & $3,13 \mathrm{c}$ & $547 \mathrm{cde}$ & $71 \mathrm{de}$ \\
Ago/06 & $3,47 \mathrm{def}$ & $3,08 \mathrm{~d}$ & $499 \mathrm{ef}$ & $59 \mathrm{def}$ \\
Set/06 & $3,46 \mathrm{ef}$ & $3,07 \mathrm{~d}$ & $693 \mathrm{a}$ & $53 \mathrm{ef}$ \\
\hline
\end{tabular}

Médias seguidas de letras diferentes na mesma coluna diferem entre si $(\mathrm{P}<0,05)$.

CCS: contagem de células somáticas; CBT: contagem bacteriana total; UFC: unidades formadoras de colônias.

A variação do teor de proteína, segundo o mês do ano, já foi apresentada na literatura, com valores variando de 2,82 a 3,25\% (Martins et al., 2006), tendo os meses de julho e setembro como os de maior e menor teor, respectivamente. Neste estudo, a amplitude de variação não foi elevada, valores mínimo e máximo de 3,07 e 3,28\%, isto é, diferença de apenas $0,21 \%$, e os meses de teores extremos não coincidiram com os do estudo de Martins et al. (2006). Para CCS e CBT, foram observados maiores valores de setembro a fevereiro (primavera/verão) e de novembro a janeiro (final da primavera/começo verão), respectivamente. Em relação aos menores valores, eles foram encontrados nos meses de março a julho para a CCS e de abril a julho, além de setembro, para CBT. Os resultados deste estudo assemelham-se aos apresentados por Smith et al. (1985): o estresse de altas temperatura e a umidade podem aumentar a suscetibilidade a infecções, bem como aumentar o número de patógenos aos quais as vacas estão expostas.

Teixeira et al. (2003) verificaram que os teores de gordura e proteína eram maiores nos meses de inverno (época seca) e menores nos meses de verão (época das águas). Como não foi possível 
identificar os meses de maiores e menores valores para os componentes do leite e seguindo o princípio da experimentação realizada por Teixeira et al. (2003), foi realizada a análise da qualidade do leite em função das estações do ano. Na Tab. 3, são apresentados os resultados de acordo com a época do ano. O outono foi a estação do ano de melhor qualidade do leite, contemplando diferença significativa $(\mathrm{P}<0,05)$ quanto à elevação do teor de gordura e proteína $\mathrm{e}$ à diminuição da CBT. Apenas na CCS não ocorreu menor valor no outono, mas sim na primavera.

Tabela 3. Valores médios para gordura, proteína, contagem de células somáticas e contagem bacteriana total das amostras analisadas por época do ano

\begin{tabular}{lcccc}
\multicolumn{1}{c}{ Época } & Gordura $(\%)$ & Proteína $(\%)$ & $\begin{array}{c}\text { CCS } \\
(1000 \text { céls } / \mathrm{mL})\end{array}$ & $\begin{array}{c}\text { CBT } \\
(1000 U F C / m L)\end{array}$ \\
\hline Primavera & $3,48 \mathrm{~b}$ & $3,13 \mathrm{c}$ & $467 \mathrm{c}$ & $207 \mathrm{a}$ \\
Verão & $3,48 \mathrm{~b}$ & $3,18 \mathrm{~b}$ & $638 \mathrm{a}$ & $89 \mathrm{~b}$ \\
Outono & $3,65 \mathrm{a}$ & $3,21 \mathrm{a}$ & $542 \mathrm{~b}$ & $57 \mathrm{c}$ \\
Inverno & $3,48 \mathrm{~b}$ & $3,10 \mathrm{~d}$ & $568 \mathrm{~b}$ & $60 \mathrm{c}$ \\
\hline
\end{tabular}

Médias seguidas de letras diferentes na mesma coluna diferem entre si $(\mathrm{P}<0,05)$.

CCS: contagem de células somáticas; CBT: contagem bacteriana total; UFC: unidades formadoras de colônias.

Com o intuito de verificar o efeito da variação climática sobre os componentes do leite, na Tab. 4 são apresentados os valores médios encontrados por estação do ano para alguns fatores climáticos. $\mathrm{O}$ outono foi a estação com os melhores valores de qualidade do leite quanto aos teores de gordura e proteína e à CBT. Esta foi a época com menores médias de temperatura e precipitação. Head (1989), Teixeira et al. (2003) e Machado (1998) verificaram efeito do clima, principalmente do verão, sobre a composição e qualidade do leite.

Tabela 4. Valores médios dos aspectos climáticos estudados para o período experimental

\begin{tabular}{lcccc}
\hline \multicolumn{1}{c}{ Época } & $\begin{array}{c}\text { Temperatura média } \\
\left({ }^{\circ} \mathrm{C}\right)\end{array}$ & $\begin{array}{c}\text { Umidade relativa } \\
\text { média }(\%)\end{array}$ & $\begin{array}{c}\text { Precipitação média } \\
(\mathrm{mm} / \text { dia })\end{array}$ & $\begin{array}{c}\text { Índice de temperatura } \\
\text { e umidade (ITU) }\end{array}$ \\
\hline Primavera & $23,79 \mathrm{~b}$ & $81,21 \mathrm{ab}$ & $3,97 \mathrm{~b}$ & $73 \mathrm{~b}$ \\
Verão & $25,23 \mathrm{a}$ & $83,72 \mathrm{a}$ & $6,34 \mathrm{a}$ & $76 \mathrm{a}$ \\
Outono & $19,46 \mathrm{~d}$ & $79,06 \mathrm{~b}$ & $0,60 \mathrm{c}$ & $66 \mathrm{c}$ \\
Inverno & $20,15 \mathrm{c}$ & $71,86 \mathrm{c}$ & $1,14 \mathrm{c}$ & $66 \mathrm{c}$ \\
\hline
\end{tabular}

Médias seguidas de letras diferentes na mesma coluna diferem entre si $(\mathrm{P}<0,05)$.

Um aspecto muito importante, ainda pouco estudado, seria o impacto desse efeito sobre a qualidade do produto, que influenciaria o programa de pagamento por qualidade, afetando diretamente o produtor rural. $\mathrm{Na}$ Tab. 5 , podem ser observados os valores parciais médios para cada componente avaliados de acordo com a tabela de pagamento por qualidade do leite proposta por Bandeira (2004).

Quanto ao pagamento por qualidade, na Tab. 5, é apresentado, também, o preço médio por litro de leite pago aos produtores dos Estados de Minas Gerais e São Paulo, bem como o valor final da bonificação/penalização pela qualidade. Observa-se que não ocorreu penalização no balanço total, pois apenas no mês de janeiro houve a penalização de $0,62 \%$ do preço por litro.
Mesmo com a variação sazonal, o produtor obteve, em média, bonificação de $4,2 \%$ por litro de leite. Entre março e junho, houve expressivo aumento na bonificação do preço por litro de leite, cujo valor máximo de bonificação ocorreu nos meses de abril e maio, acima de 8,5\%, alcançando o valor monetário de até $\mathrm{R} \$ 0,05$ por litro de leite entregue, resultado que está associado aos valores elevados de gordura e proteína do leite entregue ao laticínio.

Ao considerar somente a CCS, apenas no mês de outubro ocorreu bonificação para esse quesito avaliado. Nos outros meses, deu-se apenas penalização, com seu valor máximo no mês de janeiro. $\mathrm{Na}$ Tab. 6, apresenta-se o valor da bonificação/penalização por litro de leite em função da época do ano. 
Tabela 5. Porcentagem média de bonificação ou penalização pela qualidade de leite e os respectivos valores econômicos apresentados durante os meses do período experimental

\begin{tabular}{|c|c|c|c|c|c|c|c|}
\hline \multirow[t]{2}{*}{ Mês } & \multicolumn{4}{|c|}{$\begin{array}{c}\text { Bonificação/Penalização } \\
\text { média (\%) }\end{array}$} & \multirow{2}{*}{$\begin{array}{c}\begin{array}{c}\text { Bonificação/ } \\
\text { Penalização total }\end{array} \\
(\%)\end{array}$} & \multirow{2}{*}{$\begin{array}{c}\text { Preço médio }^{1} \\
(\mathrm{R} \$) \\
\end{array}$} & \multirow{2}{*}{$\begin{array}{c}\text { Valor monetário } \\
\text { do pagamento por } \\
\text { qualidade }\end{array}$} \\
\hline & Gordura & Proteína & $\mathrm{CCS}$ & $\mathrm{CBT}$ & & & \\
\hline Out/05 & 0,88 & 1,66 & 0,33 & $-1,66$ & $1,21 \mathrm{e}$ & 0,433 & 0,005 \\
\hline Nov/05 & 2,82 & 4,59 & $-0,66$ & $-1,79$ & $4,96 \mathrm{~cd}$ & 0,425 & 0,021 \\
\hline Dez/05 & 2,17 & 4,71 & $-2,61$ & $-3,43$ & $0,84 \mathrm{e}$ & 0,431 & 0,004 \\
\hline Jan/06 & 0,28 & 2,27 & $-3,34$ & 0,16 & $-0,62 \mathrm{e}$ & 0,451 & $-0,003$ \\
\hline Fev/06 & 1,92 & 4,96 & $-2,95$ & $-0,60$ & $3,33 d$ & 0,470 & 0,016 \\
\hline Mar/06 & 4,04 & 5,83 & $-2,30$ & 0,23 & 7,80ab & 0,511 & 0,040 \\
\hline $\mathrm{Abr} / 06$ & 4,12 & 5,56 & $-1,27$ & 0,63 & $9,04 \mathrm{a}$ & 0,554 & 0,050 \\
\hline Mai/06 & 4,47 & 4,79 & $-1,87$ & 1,07 & $8,45 \mathrm{a}$ & 0,595 & 0,050 \\
\hline Jun/06 & 3,28 & 4,33 & $-2,17$ & 0,67 & $6,11 b c$ & 0,569 & 0,035 \\
\hline Jul/06 & 2,75 & 3,59 & $-1,71$ & 0,29 & $4,91 \mathrm{~cd}$ & 0,569 & 0,028 \\
\hline Ago/06 & 2,22 & 1,87 & $-0,96$ & 0,58 & $3,71 d$ & 0,550 & 0,020 \\
\hline Set/06 & 1,82 & 1,08 & $-3,19$ & 0,92 & $0,63 \mathrm{e}$ & 0,530 & 0,003 \\
\hline Média & 2,56 & 3,77 & $-1,89$ & $-0,24$ & 4,20 & & 0,022 \\
\hline
\end{tabular}

Médias seguidas de letras diferentes na mesma coluna diferem entre si $(\mathrm{P}<0,05)$.

CCS: Contagem de células somáticas; CBT: Contagem bacteriana total.

${ }^{1}$ Preço mensal médio pago aos produtores dos Estados de Minas Gerais e São Paulo (CEPEA, 2006).

Tabela 6. Porcentagem média de bonificação ou penalização pela qualidade de leite apresentada durante as épocas do ano avaliadas

\begin{tabular}{|c|c|c|c|c|c|}
\hline \multirow[t]{2}{*}{ Mês } & \multicolumn{4}{|c|}{$\begin{array}{c}\text { Bonificação/Penalização } \\
(\%)\end{array}$} & \multirow{2}{*}{$\begin{array}{c}\text { Bonificação/Penalização } \\
\text { total }(\%)\end{array}$} \\
\hline & Gordura & Proteína & CCS & CBT & \\
\hline Primavera & 1,96 & 3,65 & $-0,98$ & $-2,30$ & $2,34 b$ \\
\hline Verão & 2,08 & 4,35 & $-2,86$ & $-0,07$ & $3,50 \mathrm{~b}$ \\
\hline Outono & 3,96 & 4,89 & $-1,77$ & 0,79 & $7,87 \mathrm{a}$ \\
\hline Inverno & 2,26 & 2,18 & $-1,95$ & 0,60 & $3,08 \mathrm{~b}$ \\
\hline
\end{tabular}

CCS: contagem de células somáticas; CBT: contagem bacteriana total.

O período de maior bonificação pela qualidade do leite produzido foi no outono, com média de bonificação de 7,9\%. O fator de maior importância para atingir esse valor foi a penalização pela contagem de células somáticas, mas também os maiores valores de bonificação para gordura e proteína.

Os teores de gordura e proteína em todas as estações favoreceram a bonificação. A CBT foi somente quesito de bonificação nos meses de outono e inverno, épocas de temperatura, umidade relativa e precipitação mais baixas e, por conseguinte, melhor índice de conforto térmico (Tab. 4).

A CCS foi o único quesito que gerou penalização ao longo das quatro estações do ano, apresentando o pico de penalização no verão. Segundo Harmon (1994), a influência da estação do ano sobre escores durante a lactação provavelmente não é causada por mudanças de temperatura e umidade, mas por exposição das extremidades dos tetos aos patógenos do ambiente, o que resulta em novas infecções. Não há evidências de que o estresse térmico aumente diretamente a CCS em glândulas saudáveis. A CCS menor no inverno e maior no verão coincide com a incidência de mastite clínica durante os meses de verão (Harmon, 1994).

De acordo com Machado (1998), a época de verão relaciona-se com elevação na porcentagem de novas infecções na glândula mamária, podendo indicar maior quantidade de bactérias presentes na superfície dos tetos e/ou menor resistência imunológica (Machado, 1998). Smith et al. (1985) relataram que o estresse de altas valores de temperatura e umidade, característico da época de verão, pode aumentar a 
suscetibilidade a infecções, bem como aumentar o número de patógenos aos quais as vacas estão expostas.

Contudo, deve ser ressaltado que o aumento das células somáticas influencia diretamente outros componentes do leite. De acordo com Politis e Ng-kwai-hang (1988), a ocorrência de mastite resulta em redução na quantidade de leite sintetizado e em mudanças nos componentes específicos do leite, reduzindo sua qualidade. Dentre os principais componentes alterados e que participam das tabelas de pagamento por qualidade, está a proteína do leite. Segundo Schultz (1977), o efeito das mastites sobre a proteína do leite é de natureza qualitativa, uma vez que os valores absolutos de proteína bruta não sofrem alterações significativas. Com isso, surge a necessidade de métodos alternativos para o pagamento do leite pela sua qualidade, porém aliados à ideia de remuneração correta ao produtor e também à do rendimento industrial. Assim, para um programa de pagamento contemplar corretamente a qualidade do leite, uma alternativa seria considerar a proporção de caseína da proteína total, que contempla tanto o componente proteína quanto a contagem de células somáticas. De acordo com Belloque e Ramos (2002), a proporção de caseína pode ser usada como parâmetro de qualidade do leite pela indústria.

\section{CONCLUSÕES}

Os meses do ano afetaram direta e indiretamente a composição do leite, a qualidade microbiológica e a ocorrência de mastite. Como resultado da influência direta ou indireta, o leite foi produzido com características que influenciaram a bonificação/penalização dos produtores que participaram de programas de pagamento por qualidade. Essa bonificação chegou a interferir no preço do leite em mais de $8,5 \%$, favorecendo os produtores comprometidos em produzir leite de qualidade. A influência da época do ano sobre o pagamento por qualidade também deve ser considerada na formulação das tabelas de pagamento. Com isso, para evitar os efeitos principalmente da contagem de células somáticas, o ideal seria trabalhar com programa de pagamento que utiliza não só o teor de proteína bruta, mas também a relação de caseína dentro do teor de proteína bruta, teor que está diretamente relacionado ao rendimento industrial e à qualidade do leite.

\section{REFERÊNCIAS BIBLIOGRÁFICAS}

ÁLVARES, J.G. Pagamento do leite por sólidos. In: VISÃO técnica e econômica da produção leiteira. Piracicaba, SP: FEALQ, 2005. p.129-140.

ALVIM, R.S.A.; MARTINS M.C. Mercado nacional e internacional do leite. In: VISÃO técnica e econômica da produção leiteira. Piracicaba, SP: FEALQ, 2005. p.7-24.

BANDEIRA, A. Leite: Pagamento por qualidade: A experiência do Pool Leite ABC. In: Seminário Estadual sobre Qualidade do Leite, 3., Castro, PR. 2004. Disponível em: $<$ http://www3.pr.gov.br/e-

parana/atp/programaleite/pdf/pagamento_qualida de.pdf>. Acessado em: 15 fev. 2006.

BARCINA, Y.; ZORRAQUINO, M.A.; PEDAUYE, J. et al. Azidiol as a preservative for milk samples. An. Vet. Murcia, v.3, p.65-69, 1987.

BELLOQUE, J.; RAMOS, M. Determination of the casein content in bovine milk by ${ }^{31} \mathrm{P}-\mathrm{NMR}$. $J$. Dairy Res., v.69, p.411-418, 2002.

DÜRR, J.W. Programa nacional de melhoria da qualidade do leite: uma oportunidade única. In: _ O COMPROMISSO com a qualidade do leite no Brasil. Passo Fundo, RS: Editora Passo Fundo, 2004. p.38-55.

FONSECA, L.M.; RODRIGUES, R.; CERQUEIRA, M.M.O.P. et al. Situação da qualidade do leite cru em Minas Gerais. In: MESQUITA, A.J.; DÜRR, J.W.; COELHO, K.O. Perspectivas e avanços da qualidade do leite no Brasil. Goiânia, GO: Talento Gráfica e Editora, 2006. p.23-37.

HARMON, R.J. Physiology of mastitis and factors affecting somatic cell counts. J. Dairy Sci., v.77, p.2103-2112, 1994.

HEAD, H.H. The strategic use of the physiological potential of the dairy cow. In: SIMPÓSIO DE LEITE NOS TRÓPICOS: NOVAS ESTRATÉGIAS DE PRODUÇÃO. Botucatu, 1989. Anais... Botucatu: UNESP/FMVZ, 1989. p.38-89. 
INSTRUÇÃO Normativa $\mathrm{n}^{\mathrm{o}} 51$, de 20 de setembro de 2002. Aprova os regulamentos técnicos de produção, identidade e qualidade do leite [do Ministério Agricultura, Pecuária e do Abastecimento]. Diário Oficial da União, Brasília, 21 set. 2002. Seção 1, p.13.

KELLY, C.F.; BOND, T.E. Bioclimatic factors and their measurement. In: KELLY, C.F.; BOND, T.E. (Ed.). A guide to environmental research on animals. Washington: National Academy of Sciences, 1971. p.7-92.

MACHADO, P.F. Efeitos da alta temperatura sobre a produção, reprodução e sanidade de bovinos leiteiros. In: SILVA, I.J.O. Ambiência na produção de leite em clima quente. Piracicaba, SP: FEALQ, 1998. p.179-188.

MARTINS, P.R.G.; SILVA, C.A.; FISCHER, V. et al. Produção e qualidade do leite na bacia de Pelotas-RS em diferentes meses do ano. Cienc. Rural, v.36, p.209-214, 2006.

MONARDES, H. Programa de pagamento de leite por qualidade em Quebéc, Canadá. In: SIMPÓSIO INTERNACIONAL SOBRE QUALIDADE DO LEITE, 1998, Curitiba-PR. Anais... Curitiba: UFPR, 1998. p.40-43.

POLITIS, I.; NG-KWAI-HANG, K.F. Association between somatic cell count of milk and cheese-yielding capacity. J. Dairy Sci., v.71, p.1720-1727, 1988.
RIBEIRO, M.E.R.; STUMPF JÚNIOR，W.; BUSS, H. Qualidade de leite. In: BITENCOURT, D.; PEGORARO, L.M.C.; GOMES, J.F. Sistemas de pecuária de leite: uma visão na região de clima temperado. Pelotas, RS: Embrapa Clima Temperado, 2000. p.175-195.

SCHULTZ, L.H. Somatic cells in milk: physiological aspects and relationship to amount and composition of milk. J. Food Prot., v.40, p.125-131, 1977.

SMITH, K.L.; TODHUNTER, D.A.; SCHOENBERGER, P.S. Environmental mastitis: cause, prevalence, prevention. J. Dairy Sci., v.68, p.1531-1553, 1985.

TEIXEIRA, N.M.; FREITAS, A.F.; BARRA, R.B. Influência de fatores de meio ambiente na variação mensal da composição e contagem de células somáticas do leite em rebanhos no Estado de Minas Gerais. Arq. Bras. Med. Vet. Zootec., v.55, p.491-499, 2003.

ZAGO, C.A.; MARTINS, T.; MACHADO, P.F. et al. Estudo da proteína instável: efeito do conservante e do armazenamento sobre o $\mathrm{pH}$ de amostras de leite. In: SIMPÓSIO INTERNACIONAL DE INICIAÇÃO CIENTÍFICA DA UNIVERSIDADE DE SÃO PAULO, 13., 2005, São Paulo, SP. Anais... São Paulo, SP: USP, 2005. CD-ROM. 